\title{
Prebiotic effect of fruit and vegetable shots containing Jerusalem artichoke inulin: a human intervention study
}

\author{
P. Ramnani ${ }^{1}$, E. Gaudier ${ }^{2}$, M. Bingham ${ }^{2}$, P. van Bruggen ${ }^{2}$, K. M. Tuohy ${ }^{1}$ and G. R. Gibson ${ }^{1}$ \\ ${ }^{1}$ Food Microbial Sciences Unit, Department of Food Microbiology, University of Reading, Reading RG6 6AP, UK \\ ${ }^{2}$ Unilever Research and Development Vlaardingen B.V., Vlaardingen, The Netherlands \\ (Received 16 September 2009 - Revised 14 January 2010 - Accepted 18 January 2010 - First published online 1 March 2010)
}

The present study aimed to determine the prebiotic effect of fruit and vegetable shots containing inulin derived from Jerusalem artichoke (JA). A three-arm parallel, placebo-controlled, double-blind study was carried out with sixty-six healthy human volunteers (thirty-three men and thirty-three women, age range: 18-50 years). Subjects were randomised into three groups $(n$ 22) assigned to consume either the test shots, pear-carrot-sea buckthorn (PCS) or plum-pear-beetroot (PPB), containing JA inulin $(5 \mathrm{~g} / \mathrm{d})$ or the placebo. Fluorescent in situ hybridisation was used to monitor populations of total bacteria, bacteroides, bifidobacteria, Clostridium perfringens/histolyticum subgroup, Eubacterium rectale/ Clostridium coccoides group, Lactobacillus/Enterococcus spp., Atopobium spp., Faecalibacterium prausnitzii and propionibacteria. Bifidobacteria levels were significantly higher on consumption of both the PCS and PPB shots (10.0 (SD 0.24) and 9.8 (SD 0.22) $\log _{10}$ cells/g faeces, respectively) compared with placebo $\left(9.3\right.$ (SD 0.42) $\log _{10}$ cells/g faeces) $(P<0.0001)$. A small though significant increase in Lactobacillus/Enterococcus group was also observed for both the PCS and PPB shots (8.3 (SD 0.49) and 8.3 (SD 0.36) $\log _{10}$ cells/g faeces, respectively) compared with placebo (8.1 (SD 0.37) $\log _{10}$ cells/g faeces) $(P=0.042)$. Other bacterial groups and faecal SCFA concentrations remained unaffected. No extremities were seen in the adverse events, medication or bowel habits. A slight significant increase in flatulence was reported in the subjects consuming the PCS and PPB shots compared with placebo, but overall flatulence levels remained mild. A very high level of compliance ( $>90 \%)$ to the product was observed. The present study confirms the prebiotic efficacy of fruit and vegetable shots containing JA inulin.

Gut microbiota: Inulin: Jerusalem artichoke: Prebiotics

The biological and clinical importance of the human gastrointestinal microbiota is becoming increasingly recognised by consumers and healthcare workers. Although many disease states involve bacterial metabolism, the human gut microbiota may be considered extremely relevant for the maintenance and improvement in host health ${ }^{(1)}$. For instance, bifidobacteria and lactobacilli may contribute to inhibit pathogenic bacteria, reduce blood cholesterol levels, improve the immune response and produce vitamins ${ }^{(2)}$. Scientific concepts underpinning directed modulation of the human gut microbiota have been developed over several decades, with probiotics as the principal focus $^{(3)}$. In recent years, there has been an upsurge of interest in prebiotics, which selectively enhance beneficial components of the gut microbiota ${ }^{(4)}$. Their use is directed towards favouring beneficial components within the gut microbial milieu such as bifidobacteria and lactobacilli. They are distinct from most dietary fibres like pectin, cellulose and xylan, which are not selectively metabolised by the gut microbiota. In contrast to probiotics, prebiotics can be added to many foods including those which are cooked or baked as they do not suffer from the survivability issues associated with probiotics ${ }^{(5,6)}$.
The fructans (i.e. neosugar, oligofructose and inulin) are current market leaders for prebiotics worldwide. Most fructans are either synthesised from sucrose or prepared commercially from inulin-rich plant sources such as chicory root (Cichorium intybus $)^{(7-9)}$. However, a number of alternative sources of inulin, such as Jerusalem artichoke (JA) (Helianthus tuberosus) ${ }^{(6)}$ and burdock (Arctium lappa) ${ }^{(10)}$ are now being commercialised, and there is growing scientific literature supportive of their equivalence to chicory-derived inulin ${ }^{(6)}$. These emerging prebiotic candidates may eventually find their way into the global market. However, there is a need to confirm their prebiotic effectiveness using reliable methodologies in different formulations and in human studies.

Here, we report a human study designed to assess the prebiotic capability of fruit and vegetable shots containing inulin from JA root. The effect of JA inulin present in the fruit and vegetable shots upon relative numbers of intestinal microbiota was determined using fluorescent in situ hybridisation (FISH). Faecal concentrations of SCFA were measured, and digestive tolerance of the prebiotic shots was monitored over the course of the trial.

Abbreviations: FISH, fluorescent in situ hybridisation; ITT, intention to treat; JA, Jerusalem artichoke; PCS, pear-carrot-sea buckthorn; PPB, plum-pear-beetroot; PP, per protocol.

* Corresponding author: Dr Priya Ramnani, fax +44 118931 0080, email p.ramnani@reading.ac.uk 


\section{Materials and methods}

\section{Subjects}

Sixty-six healthy human volunteers were recruited from the Reading area. Written consent was obtained from all the volunteers, and they were assessed for good health before the start of the trial according to the inclusion and exclusion criteria. The study protocol was reviewed and approved by the University of Reading Ethics committee.

\section{Inclusion and exclusion criteria}

Inclusion criteria. Signed consent form, age 18-50 years inclusive, non-smoking, BMI $20-30 \mathrm{~kg} / \mathrm{m}^{2}$ inclusive and good general health as determined by medical questionnaires.

Exclusion criteria. Volunteers were excluded from the trial if there was evidence of physical or mental disease or major surgery, which might limit participation in the study or completion of the study or interfere with the outcome of the study. Volunteers with a history of drug and alcohol abuse, severe allergy, abnormal drug reaction, or who were pregnant, lactating or planning pregnancy, were excluded from the study. Intake of an experimental drug within 4 weeks before study, former participation in probiotics, prebiotics or laxative trial within the previous 3 months, use of antibiotics within the previous 6 months, history of chronic constipation or diarrhoea or other chronic gastrointestinal complaint (e.g. irritable bowel syndrome) and intake of other specific prebiotics (such as fructo-oligosaccharides, galactooligosaccharides) or probiotics, drugs active on gastrointestinal motility or a laxative of any class within the 4 weeks before the start of the run-in period of the study were prohibited.

\section{Requirements for diet and medication during study}

Volunteers were instructed not to consume any additional prebiotics (such as oligosaccharides e.g. fructo-oligosaccharides or inulin), probiotics (e.g. live yoghurts), drugs active on gastrointestinal motility, antibiotics or laxatives during the study. They were not allowed to participate in any other nutritional or pharmaceutical trials for the duration of the trial. Any medication taken was recorded in the diaries. Volunteers were advised not to alter their usual diet or fluid intake during the trial period.

\section{Treatment and placebo shots}

The test and the placebo shots $(100 \mathrm{ml})$ were produced in three groups: two groups were containing JA inulin and the placebo shots did not contain inulin. The shots containing JA inulin were two liquid preparations made of fruit and vegetable juice concentrates and purées: one was predominantly made of pear-carrot-sea buckthorn and JA juices or purées (PCS), and the other preparation was predominantly made of plum-pear-beetroot and JA juices or purées (PPB). Inulin was not extracted from JA but present in the JA juice concentrate that was used in the formulation. The placebo was a water-based preparation, with added sugar, thickened and flavoured with blood orange, carrot and raspberry extracts and flavours (but no juice or purées). The nutritional information for each of the shots is given in Table 1.
Table 1. Nutritional information of placebo and fruit and vegetable test shots

\begin{tabular}{|c|c|c|c|}
\hline $\begin{array}{l}\text { Nutrients } \\
\text { (per } 100 \mathrm{ml} \text { shot) }\end{array}$ & Placebo* & $\begin{array}{c}\text { PCS test } \\
\text { shot with JA† }\end{array}$ & $\begin{array}{c}\text { PPB test } \\
\text { shot with JAf }\end{array}$ \\
\hline Energy (kJ/kcal) & $276 / 65$ & $280 / 65$ & $260 / 60$ \\
\hline Protein $(\mathrm{g})$ & Traces & 1.5 & 1.5 \\
\hline Carbohydrates (g) & $15 \cdot 8$ & 14 & 13 \\
\hline Sugars (g) & 0 & 12 & 11 \\
\hline Fat $(g)$ & 0 & 0.6 & $<0.5$ \\
\hline SFA (g) & 0 & 0.1 & 0.1 \\
\hline Cholesterol (mg) & 0.2 & 0 & 0 \\
\hline Dietary fibre $(\mathrm{g}) \S$ & 0 & 4.5 & 4.5 \\
\hline Of which inulin (g) & 0 & $2 \cdot 5$ & $2 \cdot 5$ \\
\hline $\mathrm{Na}(\mathrm{g})$ & 0.11 & 0.02 & 0.06 \\
\hline Vitamin C (mg) & 0 & 30 & 30 \\
\hline Total phenols (mg) & $<0.001$ & 96 & 148 \\
\hline
\end{tabular}

PCS, pear-carrot-sea buckthorn test shot; PPB, pear-plum-beetroot test shot; JA, Jerusalem artichoke.

*Placebo ingredients: sugar, potassium sorbate, carboxymethylated cellulose, xanthan, orange flavour, raspberry flavour, carrot flavour, $\beta$-carotene, anthocyanin, caramel, acacia gum, malic acid, citric acid, salt and water.

†PCS ingredients: pear purée, concentrated orange juice, carrot juice concentrate, JA root juice concentrate, pear juice concentrate, apple purée, orange pulp, sea buckthorn purée, acerola purée concentrate.

‡PPB ingredients: carrot juice concentrate, concentrated apple juice, JA root juice concentrate, pear purée, plum purée, beetroot juice concentrate, orange pulp, acerola purée concentrate, blackcurrant juice concentrate.

$\S$ Sum of all cellulose, non-cellulose (including hemicellulose, pectin, pentose etc.) and lignin.

The volunteers were advised to consume two of the $100 \mathrm{ml}$ shots/d. Each of the test shots provided an inulin dose of $2.5 \mathrm{~g}$, resulting in a total dose of $5 \mathrm{~g} / \mathrm{d}$.

All the test products were provided and labelled by Unilever R\&D Vlaardingen, The Netherlands. During the study, neither the investigators nor the volunteers were aware of whether they were given the treatment or placebo shots. The study was unblinded after statistical analysis.

\section{Study design}

The feeding trial comprised of a three-arm parallel, placebocontrolled, randomised, double-blind study with three groups of twenty-two healthy human volunteers. The sample size was calculated based on previous studies ${ }^{(11-14)}$, which have tested the effect of $5 \mathrm{~g}$ oligofructose supplementation on bifidobacteria. Based on these studies, it was determined that to detect an increase in bifidobacteria populations of $0.8 \log _{10}$ cells/g faeces (with $\mathrm{SD}=0.89$ and a two-sided analysis), the necessary sample size to achieve a power of 0.8 (with a significance level of $5 \%$ ) was sixty-three people (twenty-one people/group). Therefore, the study was performed with sixty-six volunteers (twenty-two per group) plus six reserve volunteers to cover potential drop-outs.

Volunteers were randomly assigned to consume either one of the two different formulations containing JA inulin (i.e. PCS, PPB) or placebo as described earlier. The three groups were balanced for sex, age and BMI. After a 2-week run-in period, they were asked to consume the products twice daily, one shot in the morning with breakfast and another in the evening with dinner for a 3-week intervention period. The treatment was followed by a 3-week wash-out period during which no shots were consumed. 
Volunteers were asked to keep diaries for baseline, treatment and wash-out periods to record stool frequency and consistency, abdominal pain, stomach or intestinal bloating and flatulence on a daily basis. Stool consistencies graded by volunteers as hard, formed and soft were scored as 0,1 and 2 , respectively. Changes in intestinal comfort (abdominal pain, stomach or intestinal bloating and flatulence) of shots qualitatively graded by volunteers as none, mild, moderate and severe were scored as 0, 1, 2 and 3, respectively. Any concomitant medication and adverse events or volunteer comments on the product were recorded. Volunteers were asked to record the time of consumption of the product in the morning and in the evening as a test product consumption check for measuring compliance. Volunteers were instructed to return the empty as well as the unused product bottles. They were considered compliant if they consumed at least $80 \%$ of the shots over the 3 weeks intervention and $100 \%$ of the shots in the last $3 \mathrm{~d}$ before the completion of the intervention.

Volunteers who completed the full intervention study according to protocol and adequate compliance were defined as 'per protocol' population (PP). Those who received at least one test product were defined as 'intention to treat' population (ITT). Five volunteers dropped out before the end of run-in and provision of a baseline sample, and they were not included in either PP or ITT populations. Only one volunteer dropped out on day 2 of the intervention and was included in the ITT population but not in the PP population. All the six dropouts were replaced by reserve volunteers maintaining the balance of the groups. The PP population (with sixty-six volunteers including the reserves who completed the study) was included in the final analysis. No separate analysis of the ITT population could be performed, as the only difference between ITT population and PP population was one volunteer who dropped out on day 2 of intervention and thus did not provide any faecal sample after the intervention started.

\section{Stool sample preparation and processing}

Freshly voided stool samples were collected in sterile plastic pots at the University of Reading at the end of run-in (day 0), treatment (day 21) and wash-out (day 42) periods, respectively. Faecal samples were processed within $15 \mathrm{~min}$ of defecation. Samples were diluted $(1: 10, \mathrm{w} / \mathrm{w})$ with sterile anaerobic PBS (0.1 M, pH 7.0) and homogenised in a stomacher (Seward, Norfolk, UK) at normal speed for $2 \mathrm{~min}$. The faecal slurry was processed for whole-cell FISH and SCFA analyses.

\section{Bacterial enumeration by fluorescent in situ hybridisation}

Changes in bacterial populations in the faecal homogenates were assessed using FISH with oligonucleotide probes targeting $16 \mathrm{~S}$ rRNA. Probes labelled with fluorescent dye $\mathrm{Cy} 3$ at $5^{\prime}$-end were synthesised commercially (Sigma Aldrich Limited, Gillingham, Kent, UK). The probes used were EUB 338 mix (EUB, EUBII and EUBIII $)^{(15,16)}$, Bac $303^{(17)}$, Bif $164^{(18)}$, His $150^{(19)}$, Erec $482^{(19)}$, Lab $158^{(20)}$, Ato $291^{(21)}$, Fpra $655^{(22)}$ and Prop $853^{(23)}$ specific for total bacteria, bacteroides, bifidobacteria, clostridia (Clostridium perfringens/histolyticum subgroup), Eubacterium rectale/Clostridium coccoides group, Lactobacillus/Enterococcus spp., Atopobium spp., Faecalibacterium prausnitzii and propionibacteria, respectively. The faecal homogenate was fixed in $4 \%$ (w/v) paraformaldehyde and hybridised with appropriate probes as described by Vulevic et al. ${ }^{(24)}$. Fifteen random fields were counted on each slide using an epifluorescent microscope (Brunel Microscopes Limited, Chippenham, Wiltshire, UK). Microbial counts were expressed as $\log _{10}$ bacterial cells per faeces (wet weight).

\section{SCFA analysis}

Aliquots, $1.5 \mathrm{ml}$, of the faecal homogenate prepared earlier were dispensed into micro centrifuge tubes and centrifuged at $12500 \mathrm{~g}$ for $5 \mathrm{~min}$. The supernatants were acidified with $6 \mathrm{M}-\mathrm{HCl}(3: 1, \mathrm{v} / \mathrm{v})$, vortexed and incubated at room temperature for $10 \mathrm{~min}$. The mix was again centrifuged at $12500 \mathrm{~g}$ for $5 \mathrm{~min}$ and filtered using a $0.2 \mu \mathrm{m}$ polyvinyl difluoride filter (Millipore, Cork, Republic of Ireland). Hundred microlitres of 2-ethylbutyric acid, used as internal standard, were added to $400 \mu \mathrm{l}$ of the sample and dispensed in a $2 \mathrm{ml}$ Hichrom vial (Agilent Technologies, South Queensferry, West Lothian, UK) for analysis.

Calibration was achieved using standard solutions of acetic, propionic, $i$-butyric, $n$-butyric, $i$-valeric, $n$-valeric and $n$-caproic acids prepared in $6 \mathrm{M}-\mathrm{HCl}$. The final concentrations of each external standard were 20,10,5, 1 and 0.5 mM. The samples were run though a 5890 Series II GC system (HP, Crawley, West Sussex, UK) fitted with a free fatty acid phase (FFAP) column $(30 \mathrm{~m} \times 0.53 \mathrm{~mm}$; J\&W Scientific, Folsom, CA, USA) and flame ionisation detector. The carrier gas, He, was delivered at a flow rate of $14 \mathrm{ml} / \mathrm{min}$. The head pressure was set at $68.95 \times 10^{3} \mathrm{~Pa}$, and split ratio was $10: 1$. Injector, column and detector were set at 220,140 and $220^{\circ} \mathrm{C}$, respectively. A quantity of $1 \mu$ l of each sample was injected with a run time of $10.75 \mathrm{~min}$. Peaks were integrated using the Atlas Lab managing software (Thermo Lab Systems, Mainz, Germany). Fatty acid concentrations were calculated by comparing their peak areas with the standards and expressed as $\mathrm{mmol} / \mathrm{g}$ (wet weight) faeces.

\section{Statistical analysis}

Statistical analysis was performed on bacterial counts $\left(\log _{10}\right.$ cells/g faeces) and fermentation characteristics using SAS software (version 9.2; SAS Institute, Inc., Cary, NC, USA). The PP population that fully completed the intervention was included in the analysis. Data are presented as arithmetic means and standard deviations, but statistical significance of the overall treatment effect was judged using the analysis of covariance analysis, with run-in data taken as a covariate. The Tukey-Kramer test was used for multiple comparisons between groups on least square means (adjusted means corrected for run-in values) in the final analysis. Similarly, group effects were also analysed at the end of the wash-out period by analysis of covariance with Tukey-Kramer for multiple comparisons, taking run-in data as covariates. For all analyses, $P<0.05$ indicated statistical significance.

\section{Results}

\section{Baseline characteristics}

Each treatment group included eleven men and eleven women. The three treatment groups placebo, PCS and PPB were not 
different from each other in terms of age (32.9 (SD 7.3), 33.0 (SD 9.1) and 32.5 (SD 7.7) years, respectively) as well as in BMI (24.3 (SD 2.4), 24.3 (SD 2.9) and 24.1 (SD 2.6) kg/m², respectively) ( $P>0 \cdot 80)$.

\section{Compliance of volunteers}

All sixty-six volunteers consumed $100 \%$ of the shots for the last $3 \mathrm{~d}$ of the intervention. Over the 3 -week period, sixty-one volunteers consumed $100 \%$ shots, four volunteers missed one shot $(>97 \%$ compliance) and one volunteer missed four shots ( $>90 \%$ compliance). All the volunteers were thus compliant according to the definition set out by the study protocol.

Table 2. Faecal bacterial numbers ( $\log _{10}$ cells/g faeces) determined by fluorescent in situ hybridisation (FISH) for sixty-six healthy human volunteers before and after consumption of pear-carrot-sea buckthorn (PCS) and plum-pear-beetroot (PPB) shots containing Jerusalem artichoke (JA) inulin or placebo

(Mean values and standard deviations)

\begin{tabular}{|c|c|c|c|c|c|c|}
\hline \multirow{2}{*}{$\begin{array}{l}\text { Treatment group ... } \\
\text { Bacterial group* }\end{array}$} & \multicolumn{2}{|c|}{ Placebo } & \multicolumn{2}{|c|}{$\begin{array}{c}\text { PCS test } \\
\text { shots with JA }\end{array}$} & \multicolumn{2}{|c|}{$\begin{array}{c}\text { PPB test } \\
\text { shots with JA }\end{array}$} \\
\hline & Mean & SD & Mean & SD & Mean & SD \\
\hline \multicolumn{7}{|l|}{ Total bacteria } \\
\hline Day $0 \dagger$ & $10 \cdot 8$ & $0 \cdot 18$ & $10 \cdot 8$ & 0.30 & $10 \cdot 8$ & 0.22 \\
\hline Day 21 & $10 \cdot 8$ & 0.26 & $10 \cdot 8$ & 0.23 & $10 \cdot 9$ & 0.18 \\
\hline Day 42 & $10 \cdot 8$ & 0.24 & $10 \cdot 8$ & 0.20 & $10 \cdot 8$ & 0.23 \\
\hline \multicolumn{7}{|l|}{ Bacteroides spp. } \\
\hline Day 0 & $9 \cdot 9$ & 0.26 & 9.9 & 0.21 & $9 \cdot 8$ & 0.32 \\
\hline Day 21 & $9 \cdot 9$ & 0.29 & 9.9 & 0.33 & 9.9 & 0.37 \\
\hline Day 42 & $9 \cdot 8$ & $0 \cdot 19$ & $9 \cdot 8$ & 0.26 & $9 \cdot 8$ & 0.42 \\
\hline \multicolumn{7}{|l|}{ Bifidobacterium spp. } \\
\hline Day 0 & $9 \cdot 3$ & 0.39 & 9.5 & 0.45 & $9 \cdot 3$ & 0.44 \\
\hline Day 21 & $9 \cdot 3^{\mathrm{a}}$ & 0.42 & $10 \cdot 0^{\mathrm{b}}$ & 0.24 & $9 \cdot 8^{\mathrm{b}}$ & 0.22 \\
\hline Day 42 & $9 \cdot 4$ & 0.43 & 9.5 & 0.36 & $9 \cdot 3$ & 0.39 \\
\hline \multicolumn{7}{|c|}{ Clostridium histolyticum/perfringens group } \\
\hline Day 0 & $8 \cdot 2$ & 0.17 & 8.2 & 0.26 & 8.2 & 0.21 \\
\hline Day 21 & $8 \cdot 2$ & 0.14 & $8 \cdot 2$ & 0.19 & $8 \cdot 1$ & 0.29 \\
\hline Day 42 & $8 \cdot 1$ & 0.15 & $8 \cdot 2$ & 0.28 & $8 \cdot 2$ & 0.23 \\
\hline \multicolumn{7}{|c|}{ Eubacterium rectale/Clostridium coccoides group } \\
\hline Day 0 & $9 \cdot 9$ & 0.24 & $10 \cdot 0$ & 0.38 & $10 \cdot 1$ & 0.35 \\
\hline Day 21 & $10 \cdot 0$ & 0.25 & $10 \cdot 0$ & 0.35 & $10 \cdot 1$ & 0.40 \\
\hline Day 42 & 9.9 & 0.29 & $10 \cdot 0$ & 0.36 & $10 \cdot 1$ & 0.31 \\
\hline \multicolumn{7}{|c|}{ Lactobacillus/Enterococcus spp. } \\
\hline Day 0 & $8 \cdot 1$ & 0.42 & $8 \cdot 2$ & 0.31 & $8 \cdot 1$ & 0.39 \\
\hline Day 21 & $8 \cdot 1^{\mathrm{a}}$ & 0.37 & $8 \cdot 3^{b}$ & 0.49 & $8 \cdot 3^{a, b}$ & 0.36 \\
\hline Day 42 & $8 \cdot 1$ & 0.38 & $8 \cdot 1$ & 0.50 & $8 \cdot 2$ & 0.34 \\
\hline \multicolumn{7}{|l|}{ Atopobium spp. } \\
\hline Day 0 & $9 \cdot 7$ & 0.25 & $9 \cdot 6$ & 0.45 & 9.5 & 0.40 \\
\hline Day 21 & $9 \cdot 6$ & 0.30 & $9 \cdot 6$ & 0.32 & $9 \cdot 6$ & 0.37 \\
\hline Day 42 & $9 \cdot 6$ & 0.29 & 9.5 & 0.30 & 9.5 & 0.35 \\
\hline \multicolumn{7}{|c|}{ Faecalibacterium prausnitzii } \\
\hline Day 0 & 9.5 & 0.32 & 9.5 & 0.32 & $9 \cdot 3$ & 0.36 \\
\hline Day 21 & $9 \cdot 6$ & 0.29 & 9.5 & 0.36 & 9.5 & 0.38 \\
\hline Day 42 & 9.5 & 0.26 & 9.4 & 0.30 & 9.4 & 0.28 \\
\hline \multicolumn{7}{|c|}{ Propionibacterium spp. } \\
\hline Day 0 & $9 \cdot 8$ & 0.31 & $10 \cdot 0$ & 0.31 & $9 \cdot 8$ & 0.34 \\
\hline Day 21 & 9.9 & 0.38 & 9.9 & 0.36 & 9.8 & 0.34 \\
\hline Day 42 & $9 \cdot 8^{\mathrm{a}}$ & 0.37 & $9 \cdot 9^{\mathrm{a}, \mathrm{b}}$ & 0.32 & $10 \cdot 0^{\mathrm{b}}$ & 0.37 \\
\hline
\end{tabular}

Day 0, run-in; day 21, treatment; day 42 , wash-out values.

a,b Mean values within a row with unlike superscript letters were significantly different ( $P<0.0001$ for Bifidobacterium spp.; $P<0.05$ for other bacterial groups)

${ }^{*}$ All bacterial group counts were assessed by FISH.

† Least square means (adjusted means after correction for the run-in value (day 0 )) have been used to determine the statistical differences between groups by analysis of covariance analysis using Tukey-Kramer for multiple comparisons. The least square means are not listed here.
Volunteers reported $100 \%$ compliance to background dietary restrictions required in the study.

\section{Medication and adverse events}

The general population of volunteers had consumed a variety of over-the-counter drugs such as remedies for cold and flu, anti-allergy, painkillers and indigestion tablets. There were no extremities, and the level of medication was judged as representative of a typical UK population. Among the sixty-six subjects, one volunteer recorded the intake of Dostinex (cabergoline), a prescription drug used to control thyroid activity.

No serious adverse events were recorded by the volunteers. Volunteers reported, in their individual diaries, a variety of symptoms, such as headache, stomach ache, toothache, backache, sore throat, scattered over the three periods (run-in, treatment and wash-out). Among the volunteers who recorded stomach pain, four specified that it was related to period pain; for others, the reasons were not stated. Two of the subjects (one each from the placebo and PPB treatment group, respectively) reported non-profuse diarrhoea which lasted for less than $2 \mathrm{~d}$.

\section{Faecal microbiota}

The faecal bacterial populations present in twenty-two volunteers in each of the three treatment groups were determined at the end of run-in, treatment and wash-out periods, respectively (Table 2). FISH with probes targeting bacterial groups of interest was used for bacterial counts. All the bacterial groups could be quantified in each sample, except lactobacilli which were below the detection limit of FISH $\left(10^{6}\right.$ cells/g) in six samples (three samples of the run-in period, two samples of the treatment period and one sample of the wash-out period). These data points were set as missing data in the statistical analysis.

Bifidobacteria levels were significantly higher upon consumption of both the PCS and PPB shots (10.0 (SD 0.24) and 9.8 (SD 0.22) $\log _{10}$ cells/g faeces, respectively) compared

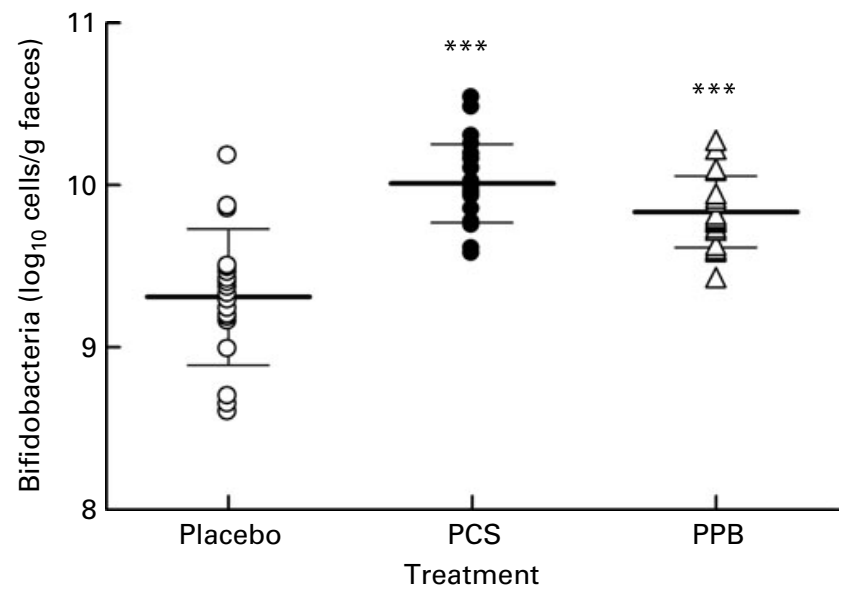

Fig. 1. Bifidobacteria counts expressed as $\log _{10}$ cells/g faeces in stool samples after the intervention period with placebo or fruit and vegetable shots (pear-carrot-sea buckthorn (PCS) and plum-pear-beetroot (PPB)) containing Jerusalem artichoke insulin. For each group, the mean (middle line), standard deviation (top and bottom lines) and individual data points are represented. ${ }^{\star \star \star}$ Mean value was significantly different from that of the placebo $(P<0.0001)$. 


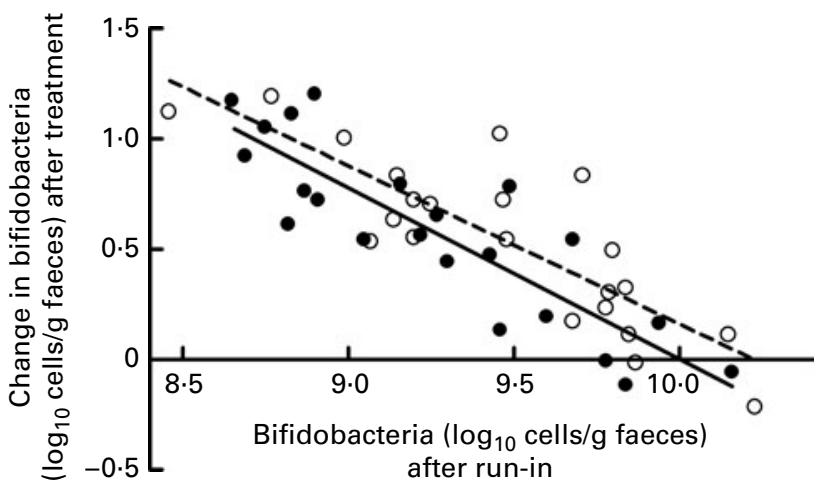

Fig. 2. Increase in bifidobacteria numbers in stool samples from pear-carrotsea buckthorn (PCS; O; ---) and plum-pea-beetroot (PPB; $\bullet$; - ) treatment groups (both shots containing Jerusalem artichoke) as a function of initial bifidobacteria levels at the end of the run-in period. The regression lines indicate that the volunteers with the lowest initial levels of bifidobacteria gave the maximum increase in bifidobacteria numbers after both the PCS and PPB treatments.

with placebo (9.3 (SD 0.42) $\log _{10}$ cells/g faeces) $(P<0.0001)$. At the end of the wash-out period, i.e. 3 weeks after the volunteers stopped consumption of the shots, the levels of bifidobacteria returned to approximate baseline levels, and no difference between the groups was observed $(P=0 \cdot 82)$. In Fig. 1, bifidobacteria counts $\left(\log _{10}\right.$ cells/g faeces as determined by FISH) are plotted from each individual volunteer containing Jerusalem artichoke (JA) inulin and placebo

(Mean values and standard deviations) after the intervention period, together with the mean and standard deviation per group. This figure clearly illustrates the strong bifidogenic effect of PCS and PPB shots. In addition, variability of the log count after product intake was significantly lower for both the test treatments than the variability of all other measurements for the same bacterial group (Table 2: SD $0 \cdot 22-0 \cdot 24$ v. $0 \cdot 36-0 \cdot 45$, respectively and Fig. 1). Finally, the volunteers with the lowest initial bifidobacteria numbers gave the largest increase in bifidobacteria numbers (Fig. 2). This may suggest that the level of bifidobacteria was maximised in the gut after treatment.

Lactobacillus/Enterococcus group levels were also slightly higher at the end of the treatment period for both the test shots (8.3 (SD 0.49) and 8.3 (SD 0.36) $\log _{10}$ cells/g faeces, respectively for PCS and PPB shots) compared with placebo (8.1 (SD 0.37) $\log _{10}$ cells/g faeces). The overall treatment effect was significant $(P=0 \cdot 042)$, although only a trend towards a significant difference between the placebo and PCS groups $(P=0.055)$ was detected in the multiple comparison.

A third possible effect of the treatments was observed in the bacterial group propionibacteria, however, we believe this is likely to be a statistical artefact. No treatment effect was found at the end of the treatment period $(P=0 \cdot 90)$. However, a treatment effect was found at the end of the wash-out period (with run-in data as covariates), due to a statistically significant difference between the placebo and PPB groups $(P<0.05)$. However, the groups were not clearly separated.

Table 3. Summary of bowel habit data and intestinal comfort recorded in diaries by sixty-six volunteers before and after consumption of pear-carrot-sea buckthorn (PCS) and plum-pear-beetroot (PPB) shots

\begin{tabular}{|c|c|c|c|c|c|c|}
\hline \multirow{2}{*}{$\begin{array}{l}\text { Treatment group ... } \\
\text { Bowel habits/intestinal comfort }\end{array}$} & \multicolumn{2}{|c|}{ Placebo } & \multicolumn{2}{|c|}{$\begin{array}{l}\text { PCS test shots } \\
\text { with JA }\end{array}$} & \multicolumn{2}{|c|}{$\begin{array}{l}\text { PPB test shots } \\
\text { with JA }\end{array}$} \\
\hline & Mean & SD & Mean & SD & Mean & SD \\
\hline \multicolumn{7}{|l|}{ Stool frequency } \\
\hline \multicolumn{7}{|l|}{ Number of stools/d } \\
\hline Day $0^{*}$ & $1 \cdot 29$ & 0.45 & $1 \cdot 33$ & 0.59 & $1 \cdot 23$ & 0.43 \\
\hline Day 21 & 1.43 & 0.57 & 1.58 & 0.67 & 1.42 & 0.50 \\
\hline Day 42 & 1.39 & 0.50 & $1 \cdot 35$ & 0.51 & $1 \cdot 28$ & 0.42 \\
\hline \multicolumn{7}{|l|}{ Stool consistency† } \\
\hline Day 0 & 0.97 & 0.27 & $1 \cdot 16$ & 0.25 & $1 \cdot 15$ & 0.29 \\
\hline Day 21 & 1.08 & 0.18 & $1 \cdot 24$ & 0.46 & $1 \cdot 26$ & 0.33 \\
\hline Day 42 & 1.03 & 0.22 & 1.09 & 0.40 & 1.06 & 0.32 \\
\hline \multicolumn{7}{|l|}{ Abdominal pain $\ddagger$} \\
\hline Day 0 & 0.07 & 0.11 & $0 \cdot 16$ & 0.22 & 0.19 & 0.28 \\
\hline Day 21 & $0 \cdot 16^{a}$ & 0.19 & $0.42^{b}$ & 0.51 & $0 \cdot 20^{a, b}$ & 0.26 \\
\hline Day 42 & 0.09 & 0.11 & $0 \cdot 23$ & 0.35 & 0.13 & 0.22 \\
\hline \multicolumn{7}{|l|}{ Stomach or intestinal bloating } \\
\hline Day 0 & 0.09 & 0.12 & 0.24 & 0.35 & 0.15 & 0.20 \\
\hline Day 21 & 0.18 & 0.27 & 0.37 & 0.49 & 0.24 & 0.30 \\
\hline Day 42 & 0.08 & 0.14 & 0.29 & 0.46 & 0.26 & 0.48 \\
\hline \multicolumn{7}{|l|}{ Flatulence } \\
\hline Day 0 & 0.46 & 0.52 & 0.57 & 0.44 & 0.60 & 0.55 \\
\hline Day 21 & $0.44^{\mathrm{a}}$ & 0.51 & $0.98^{b}$ & 0.73 & $0.83^{a, b}$ & 0.67 \\
\hline Day 42 & $0.52^{a, b}$ & 0.49 & $0.68^{a}$ & 0.52 & $0.45^{\mathrm{b}}$ & 0.44 \\
\hline
\end{tabular}

Day 0, run-in; day 21, treatment; day 42, wash-out. Average values over the three periods have been represented here.

${ }_{\mathrm{a}, \mathrm{b}}$ Mean values within a row with unlike superscript letters were significantly different $(P<0.05)$.

* Least square means (adjusted means after correction for the run-in value (day 0)) have been used to determine the statistical differences between groups by analysis of covariance analysis using Tukey-Kramer for multiple comparisons. The least square means are not listed here.

† Stool consistencies graded as hard, formed and soft were scored as 0,1 and 2, respectively.

‡Intestinal comfort (abdominal pain, stomach or intestinal bloating and flatulence) graded as none, mild, moderate and severe were scored as $0,1,2$ and 3 , respectively. 
This suggests that there was no real effect of the shot treatment on propionibacterial populations.

For other groups of enumerated bacterial populations (total bacteria, bacteroides, clostridia, E. rectale/C. coccoides group, Atopobium spp. and $F$. prausnitzii), overall no significant differences were observed.

\section{Bowel habits and intestinal comfort}

Table 3 summarises data on bowel habits and intestinal comfort. No significant differences were observed in the mean daily stool frequency. Average stool scores graded hard, formed and soft are depicted in Table 3 with no significant differences observed. The parameters of intestinal comfort (abdominal pain, stomach or intestinal bloating and flatulence) graded by volunteers as none, mild, moderate and severe are also depicted in Table 3. No significant changes in scores of stomach or intestinal bloating were observed after treatment compared with placebo. A treatment effect on abdominal pain scores was found $(P=0 \cdot 03)$, due to a slightly higher score in the PCS group as compared with placebo at the end of the treatment period ( 0.42 (SD 0.51) v. $0 \cdot 16$ (SD 0.19) on a scale of $3, P=0.03$ ). This small, but significant effect, was due to slightly higher mean scores $(1 \cdot 4-1 \cdot 6)$ for three volunteers in the PCS group after treatment. There was no significant difference in abdominal pain scores between the PPB group and placebo group. Overall, the scores still remained in the range of 'mild' ratings. Flatulence scores were also affected by the treatments $(P=0.018)$, due to a statistically significant difference between the PCS and placebo groups (0.98 (SD 0.73) v. 0.44 (SD 0.51), $P=0.02$ ). There was no difference in flatulence scores between the PPB and placebo groups at the end of the treatment period. In all the groups, levels of flatulence after treatment remained mild (mean scores below 1 on a scale of 3 ).

\section{SCFA analysis}

Parallel to the bacterial counts, faecal samples were also analysed for SCFA (Table 4). The average molar proportion of acetic, propionic and butyric acids varied from 81.1 to 91.6 , 1.06 to 14 and 2.0 to $9.4 \%$, respectively. All other fatty acids namely isobutyric, valeric, isovaleric and caproic were below the detection limits. No significant changes in faecal concentrations of any SCFA were observed over the course of the study.

\section{Discussion}

Inulin-derived fructans are well characterised and have emerged as the most confirmed group of prebiotics, a fact supported in several human studies ${ }^{(6,14,25)}$. However, most research has been restricted to inulin derived from chicory $\operatorname{roots}^{(9)}$. There is growing interest in alternative sources of inulin such as JA. Kleessen et al. ${ }^{(6)}$ confirmed its prebiotic effectiveness and equivalence to chicory inulin in snack bars. Since there is relatively little information on the effects of JA on gut microbiota, there is a need to confirm prebiotic efficacy in different food formulations in vivo.

The present study thus aimed to determine the effect of a fruit and vegetable shot containing inulin from JA on the gut microbiota of sixty-six healthy human volunteers. The study was carried out in a double-blind, randomised, parallel manner, with volunteers consuming the test products for a 3 -week period, followed by a 3-week wash-out period. The test shots were delivered in two different flavours PCS and PPB. The total dose of inulin consumed by the volunteers was $5 \mathrm{~g} / \mathrm{d}$. The primary objective of the study was to monitor changes in levels of the following faecal bacterial populations: total bacteria, bacteroides, bifidobacteria, clostridia, E. rectale/ C. coccoides group, Lactobacillus/Enterococcus spp., Atopobium spp., F. prausnitzii and propionibacteria using FISH.

Table 4. Ratios of SCFA in the faecal samples of volunteers before and after consumption of pear-carrot-sea buckthorn (PCS) and plum-pear-beetroot (PPB) shots containing Jerusalem artichoke (JA) inulin and placebo

(Molar ratio and standard deviations)

\begin{tabular}{|c|c|c|c|c|c|c|}
\hline \multirow{2}{*}{$\begin{array}{l}\text { Treatment group ... } \\
\text { SCFA }^{*}\end{array}$} & \multicolumn{2}{|c|}{ Placebo } & \multicolumn{2}{|c|}{$\begin{array}{l}\text { PCS test shots } \\
\text { with JA }\end{array}$} & \multicolumn{2}{|c|}{$\begin{array}{l}\text { PPB test shots } \\
\text { with JA }\end{array}$} \\
\hline & Molar ratio & SD & Molar ratio & SD & Molar ratio & SD \\
\hline \multicolumn{7}{|l|}{ Acetic acid } \\
\hline Day 0† & $85 \cdot 7$ & $14 \cdot 3$ & $90 \cdot 4$ & $11 \cdot 3$ & $86 \cdot 8$ & $18 \cdot 1$ \\
\hline Day 21 & $81 \cdot 1$ & 22.5 & $89 \cdot 8$ & 10.9 & 91.6 & 8.9 \\
\hline Day 42 & $87 \cdot 6$ & $15 \cdot 2$ & 87.9 & $12 \cdot 5$ & $86 \cdot 8$ & 13.5 \\
\hline \multicolumn{7}{|l|}{ Propionic acid } \\
\hline Day 0 & 8.5 & 8.5 & $5 \cdot 4$ & $6 \cdot 7$ & 8.4 & $13 \cdot 8$ \\
\hline Day 21 & $14 \cdot 0$ & $21 \cdot 2$ & $6 \cdot 4$ & 8.4 & $6 \cdot 4$ & $7 \cdot 7$ \\
\hline Day 42 & $7 \cdot 2$ & 8.5 & $7 \cdot 7$ & $9 \cdot 8$ & 9.4 & 11.6 \\
\hline \multicolumn{7}{|l|}{ Butyric acid } \\
\hline Day 0 & $5 \cdot 8$ & 7.4 & $4 \cdot 3$ & $7 \cdot 4$ & 4.7 & 7.9 \\
\hline Day 21 & 4.8 & 8.5 & $3 \cdot 2$ & $5 \cdot 2$ & $2 \cdot 0$ & 4.4 \\
\hline Day 42 & $5 \cdot 1$ & 8.2 & 4.4 & $6 \cdot 7$ & 3.7 & 6.7 \\
\hline
\end{tabular}

Day 0, run-in; day 21, treatment; day 42 , wash-out values.

* SCFA represented as ratio (\%) of individual SCFA concentration in $\mathrm{mmol} / \mathrm{g}$ of faeces/total SCFA concentration in mmoles/gram of faeces.

$†$ No significant differences between treatment groups were found. Least square means (adjusted means after correction for the run-in value (day 0)) have been used to determine the statistical differences between groups by analysis of covariance analysis using Tukey-Kramer for multiple comparisons. The least square means are not listed here. 
The secondary objective was to measure concentrations of SCFA, analyse bowel habits and intestinal comfort. All changes were monitored over the course of the trial on day 0 (end of run-in), day 21 (end of treatment) and day 42 (end of wash-out).

Sixty-six volunteers completed the study with a very high compliance $(>90 \%)$ to the test products and $100 \%$ compliance to background diet with restrictions in the consumption of prebiotic and probiotic foods. No extremities in medication or adverse events were observed. Only one volunteer reported the intake of a prescription drug (Dostinex) to prevent excess thyroid activity. Since no literature data could be found to indicate that this drug has an effect on the gut microbiota, this volunteer was not excluded from the 'PP' population.

In the present study, consumption of both the PCS and PPB shots containing JA inulin resulted in a clear and significant increase in bifidobacteria compared with placebo (Fig. 1). The prebiotic effectiveness of JA inulin observed here is well in line with previous feeding studies, where chicoryderived ingredients have been used ${ }^{(6,14,25)}$. However, the increase in bifidobacteria numbers over time was lower than that obtained for JA inulin containing snack bars reported by Kleessen et al. ${ }^{(6)}$ Here, an increase in bifidobacteria numbers of $1.2 \log _{10}$ cells/g faeces in $21 \mathrm{~d}$ was observed in comparison to an increase of $0.5-0.6 \log _{10}$ cells/g faeces for a similar intervention period in the present study. This may be attributed to the higher dose of JA inulin (7.7-14.5 g/d) used in the snack bars or to the baseline bifidobacteria levels of volunteers which were much lower $\left(8.5 \log _{10}\right.$ cells/g faeces) than the numbers observed in the present study $\left(9 \cdot 3-9.4 \log _{10}\right.$ cells/g faeces). It was also observed that bifidobacteria numbers returned to original baseline levels at the end of wash-out period. This is consistent with previous reports ${ }^{(5,7,9,26,27)}$ which also demonstrated a similar effect. The greatest increase in bifidobacteria populations was observed in individuals with the lowest baseline levels (Fig. 2) which is also well documented ${ }^{(14,26,28)}$.

Unlike the clear bifidogenic effect, a small increase in Lactobacillus/Enterococcus group was also observed for both the test shots compared with placebo: $0 \cdot 2 \log _{10}$ cells/g faeces for both the PCS and PPB shots compared with placebo. This is consistent with a few studies on fructo-oligosaccharides, where increases in lactobacilli have also been observed ${ }^{(25)}$. However, Kleessen et al. ${ }^{(6)}$ report on JA snack bars did not show any change in the lactobacilli/enterococci populations.

No change in numbers of total bacteria, bacteroides, clostridia, E. rectale/C. coccoides group and Atopobium spp. were observed. This was contrasting to the decrease in levels of potential pathogenic groups such as bacteroides and clostridia reported by Kleessen et al. ${ }^{(6)}$ for JA inulin. However, studies with other inulin-based products report little or no significant changes in other groups of bacteria apart from bifidobacteria $^{(5,8,14,26)}$. F. prausnitzii levels remained unchanged after the treatment, which is consistent with the report by Kleessen et al. ${ }^{(6)}$. The difference between groups observed with propionibacteria was seen after the wash-out period but not the treatment period and seemed to be a statistical artefact. No changes in bacterial populations were observed on ingestion of the placebo shots.

No significant changes were observed in the faecal SCFA concentrations after consumption of PCS or PPB shots containing JA inulin. It has been well documented in human studies that approximately $95 \%$ of the SCFA are readily absorbed by the large intestine before excretion in the faeces. Thus, their concentration in the faeces is unlikely to represent their rate of production by the gut microbiota ${ }^{(6,29)}$.

Inulin type fructans are well known to stimulate bowel movements ${ }^{(6,7,14)}$. In the present study, no significant change in stool frequency or consistency was observed, and no extremities were observed for intestinal comfort reports. No significant changes in stomach or intestinal boating were observed. Moderate increased abdominal pain was reported for three volunteers consuming the PCS shots, but not for the PPB shots. These three volunteers remained compliant to the intervention. Overall, abdominal pain levels remained low. A significant increase in flatulence reports was observed for volunteers consuming the PCS shots. However, levels of flatulence remained mild. The production of hydrogen during bacterial fermentation may be the reason for flatulence. However, the bacterial groups whose numbers increased significantly, namely bifidobacteria and lactobacilli, are not known to produce gas ${ }^{(30)}$. In contrast, clostridia, which are prolific gas producers, did not show any significant increase upon ingestion of the prebiotic shots. Overall, the relationship between specific bacteria in the gut and gas production is not well understood ${ }^{(5,6,14,31)}$.

In conclusion, the study confirms the prebiotic effectiveness of fruit and vegetable shots containing JA inulin as observed by selective increase in bifidobacteria populations and a small increase in lactobacilli. The novel combination of a fruit and vegetable shot with the bacterial modulatory capability of JA inulin constitutes a new food format to deliver functional benefits consisting of natural ingredients.

\section{Acknowledgements}

The present study was financially supported by Unilever R\&D, Vlaardingen, The Netherlands. P. R. wrote the manuscript and carried out the full study as well as all the experimental analyses. E. G., M. B., K. M. T. and G. R. G. designed the study and contributed to the manuscript. P. v. B. performed the statistical analyses and contributed to the manuscript. There were no conflicts of interest among the authors. We thank Sensory Dimensions, Science and Technology Centre, Reading for distributing recruitment letters and Ms Jan Luff of the Hugh Sinclair Clinical Unit, Department of Food Biosciences, University of Reading for her help in recruiting volunteers. We are grateful to all the volunteers for provision of stool samples for the study.

\section{References}

1. Gibson GR \& Roberfroid MB (1999) Colonic microbiota, Nutrition and Health. Dordrect: Kluwer Academic Publishers.

2. Steer T, Carpenter H, Tuohy K, et al. (2000) Perspectives on the role of the human gut microbiota and its modulation by pro- and prebiotics. Nutr Res Rev 13, 229-254.

3. Fuller R \& Gibson GR (1997) Modification of the intestinal microflora using probiotics and prebiotics. Scand J Gastroenterol Suppl 222, 28-31.

4. Gibson GR \& Roberfroid MB (1995) Dietary modulation of the human colonic microbiota: introducing the concept of prebiotics. J Nutr 125, 1401-1412. 
5. Tuohy KM, Kolida S, Lustenberger AM, et al. (2001) The prebiotic effects of biscuits containing partially hydrolysed guar gum and fructo-oligosaccharides - a human volunteer study. Br J Nutr 86, 341-348.

6. Kleessen B, Schwarz S, Boehm A, et al. (2007) Jerusalem artichoke and chicory inulin in bakery products affect faecal microbiota of healthy volunteers. Br J Nutr 98, 540-549.

7. Gibson GR, Beatty ER, Wang X, et al. (1995) Selective stimulation of bifidobacteria in the human colon by oligofructose and inulin. Gastroenterology 108, 975-982.

8. Kleessen B, Sykura B, Zunft HJ, et al. (1997) Effects of inulin and lactose on fecal microflora, microbial activity, and bowel habit in elderly constipated persons. Am J Clin Nutr $\mathbf{6 5}$, 1397-1402.

9. Roberfroid MB (2005) Introducing inulin-type fructans. $\mathrm{Br} J$ Nutr 93, Suppl. 1, S13-S25.

10. Li D, Kim JM, Jin Z, et al. (2008) Prebiotic effectiveness of inulin extracted from edible burdock. Anaerobe 14, 29-34.

11. Rao VA (2001) The prebiotic properties of oligofructose at low intake levels. Nutr Res 21, 843-848.

12. Bouhnik Y, Raskine L, Simoneau G, et al. (2006) The capacity of short-chain fructo-oligosaccharides to stimulate faecal bifidobacteria: a dose-response relationship study in healthy humans. Nutr J 5, 8 .

13. Bouhnik Y, Raskine L, Champion K, et al. (2007) Prolonged administration of low-dose inulin stimulates the growth of bifidobacteria in humans. Nutr Res 27, 187-193.

14. Kolida S, Meyer D \& Gibson GR (2007) A double-blind placebo-controlled study to establish the bifidogenic dose of inulin in healthy humans. Eur J Clin Nutr 61, 1189-1195.

15. Amann RI, Binder BJ, Olson RJ, et al. (1990) Combination of 16S rRNA-targeted oligonucleotide probes with flow cytometry for analyzing mixed microbial populations. Appl Environ Microbiol 56, 1919-1925.

16. Daims H, Bruhl A, Amann R, et al. (1999) The domain-specific probe EUB338 is insufficient for the detection of all bacteria: development and evaluation of a more comprehensive probe set. Syst Appl Microbiol 22, 434-444.

17. Manz W, Amann R, Ludwig W, et al. (1996) Application of a suite of 16S rRNA-specific oligonucleotide probes designed to investigate bacteria of the phylum cytophaga-flavobacterbacteroides in the natural environment. Microbiology 142, 1097-1106.

18. Langendijk PS, Schut F, Jansen GJ, et al. (1995) Quantitative fluorescence in situ hybridization of Bifidobacterium spp. with genus-specific 16S rRNA-targeted probes and its application in fecal samples. Appl Environ Microbiol 61, 3069-3075.
19. Franks AH, Harmsen HJ, Raangs GC, et al. (1998) Variations of bacterial populations in human feces measured by fluorescent in situ hybridization with group-specific 16S rRNA-targeted oligonucleotide probes. Appl Environ Microbiol 64, 3336-3345.

20. Harmsen HJ, Gibson GR, Elfferich P, et al. (2000) Comparison of viable cell counts and fluorescence in situ hybridization using specific rRNA-based probes for the quantification of human fecal bacteria. FEMS Microbiol Lett 183, 125-129.

21. Harmsen HJ, Wildeboer-Veloo AC, Grijpstra J, et al. (2000) Development of $16 \mathrm{~S}$ rRNA-based probes for the Coriobacterium group and the Atopobium cluster and their application for enumeration of Coriobacteriaceae in human feces from volunteers of different age groups. Appl Environ Microbiol 66, 4523-4527.

22. Hold GL, Schwiertz A, Aminov RI, et al. (2003) Oligonucleotide probes that detect quantitatively significant groups of butyrate-producing bacteria in human feces. Appl Environ Microbiol 69, 4320-4324.

23. Walker AW, Duncan SH, McWilliam Leitch EC, et al. (2005) $\mathrm{pH}$ and peptide supply can radically alter bacterial populations and short-chain fatty acid ratios within microbial communities from the human colon. Appl Environ Microbiol 71, 3692-3700.

24. Vulevic J, Drakoularakou A, Yaqoob P, et al. (2008) Modulation of the fecal microflora profile and immune function by a novel trans-galactooligosaccharide mixture (B-GOS) in healthy elderly volunteers. Am J Clin Nutr 88, 1438-1446.

25. Kolida S \& Gibson GR (2007) Prebiotic capacity of inulin-type fructans. J Nutr 137, 2503S-2506S.

26. Tuohy KM, Finlay RK, Wynne AG, et al. (2001) A human volunteer study on the prebiotic effects of HP-inulin-faecal bacteria enumerated using fluorescent in situ hybridisation (FISH). Anaerobe 7, 113-118.

27. Kruse HP, Kleessen B \& Blaut M (1999) Effects of inulin on faecal bifidobacteria in human subjects. Br J Nutr 82, $375-382$.

28. Roberfroid MB, Van Loo JA \& Gibson GR (1998) The bifidogenic nature of chicory inulin and its hydrolysis products. J Nutr 128, $11-19$.

29. Costabile A, Klinder A, Fava F, et al. (2008) Whole-grain wheat breakfast cereal has a prebiotic effect on the human gut microbiota: a double-blind, placebo-controlled, crossover study. $\mathrm{Br} \mathrm{J}$ Nutr 99, 110-120.

30. Probert HM \& Gibson GR (2002) Investigating the prebiotic and gas-generating effects of selected carbohydrates on the human colonic microflora. Lett Appl Microbiol 35, 473-480.

31. Cummings JH \& Macfarlane GT (2002) Gastrointestinal effects of prebiotics. Br J Nutr 87, Suppl. 2, S145-S151. 